\title{
Europe makes do without NASA
}

\section{US budget crisis forces European Space Agency to abandon plans for joint mission.}

\section{BY EUGENIE SAMUEL REICH}

$\mathrm{T}$

The European Space Agency (ESA) is pushing ahead without NASA support for its next big science mission, as the ongoing US budget crunch and competing priorities impose serious constraints on the US space agency (see Nature 471, 278; 2011). ESA last week told leaders of three large, or 'L-class', missions that are competing for funding to revise their proposals by leaving out the substantial US contribution that had previously been assumed.

"The decision was made very reluctantly," says David Southwood, director of science and robotic exploration at ESA. "NASA could not meet our timetable to launch."

The budget available to the winning L-class mission, set to launch in 2020, will be cut by $40-50 \%$ to a round figure of $€ 700$ million (US\$996 million). The competing missions are the International X-ray Observatory (IXO), a telescope that would observe black holes and the formation of galaxies; the Laser Interferometer Space Antenna (LISA), which would detect gravitational waves; and the Europa Jupiter System Mission (EJSM-Laplace), in which twin probes would head to Jupiter's icy moons Europa and Ganymede. ESA had planned to choose a winner in June, but it has now put off the decision until February 2012 while teams rework their proposals.

The reduced budget will affect the science capabilities of each mission, but team leaders are optimistic. Joel Bregman, a member of the science definition team for IXO, says that even if the telescope is built with a smaller mirror than planned and only two or three instruments instead of the proposed six, it will still be a step ahead of current X-ray missions. And Karsten Danzmann, European co-chairman of the LISA international science team, says that a more modest LISA could still detect gravitational waves, but would be sensitive to waves emanating from fewer kinds of astrophysical source.

Ronald Greeley, US co-chairman of the EJSM-Laplace science team, says that his group's mission may be the easiest to rework, because it involves two spacecraft. The NASA-led Europa probe could be dropped - although the mission would lose much of its scientific appeal.

NASA still hopes to contribute in smaller ways to ESA's L-class mission, but it faces shortfalls with a flagship programme of its own: James Green, director of NASA's planetaryscience division, told an advisory committee on 16 March that under President Barack Obama's 2012 budget request, the agency has about $\$ 1$ billion to commit to phase one of its top planetary-science priority, a sample-return mission to Mars. The mission is expected to cost far more, so it will not be able to go forward without a comparable contribution from ESA. A bilateral meeting between NASA and ESA officials is set for 29-30 March in Pasadena, California. 